\title{
Satellite Observed Environmental Changes over the Qinghai-Tibetan Plateau
}

\author{
Kuo-Hsin Tseng ${ }^{1, *}$, C. K. Shum ${ }^{1}$, Hyongki Lee ${ }^{1}$, Jianbin Duan $^{1}$, Chungyen Kuo ${ }^{2}$, \\ Shuli Song ${ }^{3}$, and Wenyao Zhu ${ }^{3}$ \\ ${ }^{1}$ Division of Geodetic Science, School of Earth Sciences, Ohio State University, Ohio, USA \\ ${ }^{2}$ National Cheng Kung University, Tainan, Taiwan \\ ${ }^{3}$ Shanghai Astronomical Observatory, Shanghai, China
}

Received 6 April 2010, accepted 17 September 2010

\begin{abstract}
We use satellite observed and model atmospheric variables, including land surface temperature, snowfall, snow extent, precipitation, and water vapor contents to study the feasibility of quantifying anthropogenic climate change over high elevation areas such as the Qinghai-Tibetan Plateau. Five types of satellite data and outputs from Atmospheric General Circulation Model (AGCMs) are used to study these climate change indicators: (1) AIRS/AMSU/HSB atmospheric sounding system onboard the Aqua platform, $2003 \sim 2009$, (2) Moderate Resolution Imaging Spectroradiometer (MODIS) onboard Terra, $2001 \sim 2009$, (3) The Tropical Rainfall Measuring Mission (TRMM) precipitation measurements, 1999 2009, (4) the ERAinterim (ECMWF Interim Reanalysis), $1989 \sim 2009$, and (5) the Japanese 25-year Reanalysis Project (JRA-25) AGCM data, $1979 \sim 2009$. We find that biases exist between temperature observations and model data $0.29 \sim 3.12^{\circ} \mathrm{C}$, AIRS and JRA-25, respectively. The trends for each of the atmospheric variables at best have a qualitative agreement, presumably because the data spans of satellite observations are too short ( $7 \sim 10$ years). The temperature trends for $4000 \sim 5000 \mathrm{~m}$ over the Plateau are estimated to be $0.01 \sim 0.05^{\circ} \mathrm{C} \mathrm{yr}^{-1}$, qualitatively agreeing with the published rate of $0.3^{\circ} \mathrm{C} \mathrm{decade}^{-1}$ over the last three decades using in situ data.
\end{abstract}

Key words: Tibetan Plateau, Climate change, Remote sensing

Citation: Tseng, K. H., C. K. Shum, H. Lee, J. Duan, C. Kuo, S. Song, and W. Zhu, 2011: Satellite observed environmental changes over the Qinghai-Tibetan Plateau. Terr. Atmos. Ocean. Sci., 22, 229-239, doi: 10.3319/TAO.2010.09.17.03(TibXS)

\section{INTRODUCTION}

During the past several decades, the changes in climate patterns on a global scale due to anthropogenic effects have raised the attention of intergovernmental organizations to assess the impact and tendency of global warming (Hansen and Lebedeff 1987; Le Treut et al. 2007). Numerous endeavors contributed by scientific groups unveiled significant changes of climate system interacting between the troposphere and the cryosphere (Lemke et al. 2007), and other Earth systems. Among all surface types, high mountain regions are responding more sensitively to climate change with respect to glacial morphology (Barry 1990), hydrodynamics (Beniston 1994), and to thermal (Shrestha et al. 1999) changes. With an averaged elevation over $4000 \mathrm{~m}$ above mean sea level, the Qinghai-Tibetan Plateau (TP)

\footnotetext{
* Corresponding author

E-mail: tseng.95@osu.edu
}

and its surroundings (Fig. 1) have the most alpine glaciers in the world and are justifiably being called the Third Pole (Qiu 2008), and the World Water Tower (Xu et al. 2008). Recent studies have concluded that the climate on the Tibetan Plateau is changing rapidly, significantly influenced by changing monsoon systems, melting alpine glaciers and permafrost degradation leading to impacts on hydrologic processes and water resources (Yao et al. 2007). According to the analysis of in situ meteorological data record, the area over the Tibetan Plateau at an altitude above $4000 \mathrm{~m}$ has been warming at a rate of $0.3^{\circ} \mathrm{C}$ per decade over the past three decades, which is twice the rate of the observed global warming (Liu and Chen 2000; Xu et al. 2008).

The atmospheric variables associated with the climate change include land surface temperature (LST), precipitation, water vapor, snow cover and snow depth, which are among the consequences of complex processes resulting from anthropogenic climate change (Solomon et al. 2007). 


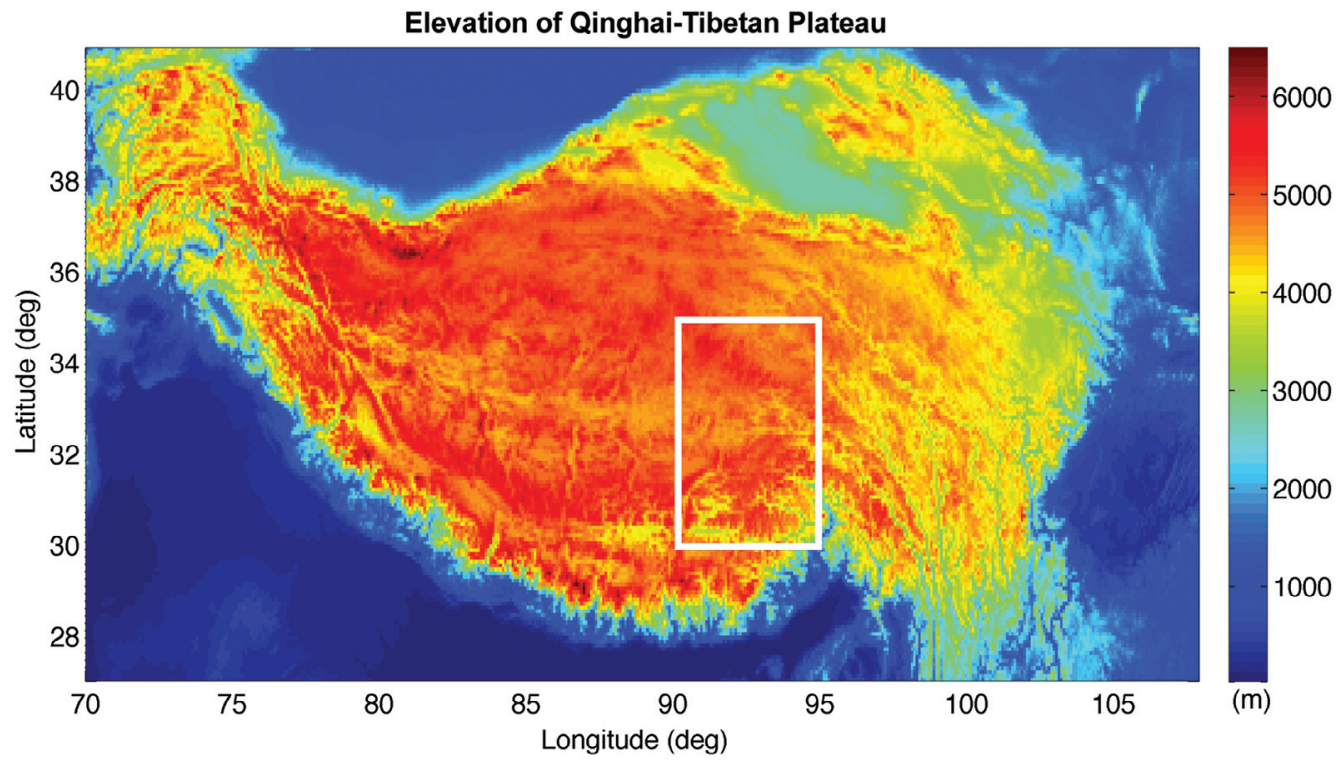

Fig. 1. Smoothed elevation map with approximate resolution of $8 \mathrm{~km}$. Computed from 30 arcsecond GTOPO30 global elevation model. White rectangle indicates the region for the study of observed and modeled temperature differences between various data sets (Fig. 2).

The observed (air, land surface, and sea surface) temperature trend has been estimated to be increasing regionally (e.g., over India, Hingane et al. 1985) and globally (Solomon et al. 2007). An observed shrinkage of snow extent over the Tibetan Plateau is linked to physical mechanisms associated with temperature and precipitation variations ( $\mathrm{Wu}$ and Qian 2003). It is also stated in the recent Intergovernmental Panel on Climate Change (IPCC) Fourth Assessment Report (AR4) that the snow fall and extent have been decreasing over the last few decades in the Northern hemisphere (Lemke et al. 2007).

The microwave radiometer based Earth-orbiting satellites are abundant, including the more contemporary satellite data sets onboard NASA's Earth Observing System (EOS) Terra and Aqua platforms, and provide global measurements of land surface temperature, snow extent and other atmospheric variables with fine spatial and temporal resolutions since 2003. Sophisticated Atmospheric General Circulation Models (AGCMs), in particular, the so-called reanalysis data products, assimilate some of the satellite observations and are becoming increasing accurate. Despite the relatively short duration of data collection, 2003 $\sim 2009$, as much longer span is needed for studying climate change, this study analyzes a number of the climatic or environmental variables based on satellite observations and AGCM output over the Tibetan Plateau. The objective of the study is to provide comparisons of satellite-observed and model-based rate of temperature, precipitation, snow depth/extent, and water vapor, and their spatial variations over the Tibetan Plateau, 1979 2009 (longest model data span), towards the assessment of climate change impacts on the Plateau.

\section{DATA AND METHODS}

\subsection{Data}

In this study, we choose data from two Atmospheric General Circulation Models (AGCMs) and from three ongoing satellite missions to examine a number of atmospheric variables over the Tibetan Plateau, namely ERAinterim and JRA-25, and MODIS/Terra, TRMM, and AIRS/ AMSU/HUB/Aqua, respectively. The purpose is to compare the atmospheric observations or model predictions over the Tibetan Plateau, an unique region between the troposphere and the stratosphere. The high elevation $(\sim 4000 \mathrm{~m})$ of the Plateau allows more distinct measurements of land surface temperature (LST), i.e., the 4-km LST, standard height for measuring temperature change due to global warming.

ERA-interim is currently the major ECMWF project developed to reanalyze the historical data after decades of operation following ERA-15 (1979 1993) and ERA-40 (1957 2002) (Dee and Uppala 2009). The main interest of ERA-interim is to describe the seasonal cycle and spatial change of the atmospheric condition. This project merges the last two projects and exploits the 4D-variational (4DVar) data assimilation to produce a new generation of reanalysis system since 1989. Major dynamic fields have applied a T255 spherical-harmonic interpolation and a N128 reduced Gaussian grid to obtain an uniform spacing of approximate $79 \mathrm{~km}$. However, the GRIdded Binary (GRIB) data we adopted in this study have been reduced to $1.5^{\circ} \times$ $1.5^{\circ}$ grid.

The Japanese 25-year reanalysis (JRA-25) operated by Japan Meteorological Agency is the first long-term reanalysis project conducted in Asia (Onogi et al. 2007). Over 100 
atmospheric variables retrieved from orbital satellite microwave radiometer, sounders, and ground-based observational network are incorporated in a 3D-variational (3D-Var) data assimilation scheme. The reanalysis and forecast fields cover the time period from 1979 to present. The 3D-Var data assimilation system used in JRA-25 provides data products with a horizontal resolution of $1.125^{\circ} \times 1.125^{\circ}$ and 40 vertical layers.

Data from three remote-sensing satellite missions are utilized in this study. The MODIS/Terra is an Earth monitoring project focused on the thermal and compositional change in the atmosphere. Launched in December 1999, the Terra (EOS AM-1) satellite with a near polar inclination $\left(98.2^{\circ}\right)$ and sun-synchronous orbit extends the scientific data to a new multi-decades era that addresses the need to explain numerous unsolved climate and environmental problems. Taking advantage of the sun-synchronous orbit, two equatorial crossing time periods (10:30 PM and 10:30 AM local time) provide ideal approaches to efficiently sample atmospheric variables, which have diurnal variation, within few cycles. Launched in late 1997, TRMM (Tropical Rainfall Measuring Mission) equipped with both active and passive microwave radiometers is a mission jointly operated between NASA and Japanese Space Agency (JAXA). With a ground track between $35^{\circ} \mathrm{N}$ and $35^{\circ} \mathrm{S}$, a low orbit $(400 \mathrm{~km})$, and a cycle period of about 91 minutes, TRMM is capable of not only monitoring the various types of tropical rainfall such as monsoon, storms, and cyclones, but also intensively filling the data gaps that are missed by other longer temporal sampling or sun-synchronized satellites.

The AIRS/AMSU/HUB (hereafter, AIRS) contains atmospheric products derived from the ASTER (Advanced Spaceborne Thermal Emission and Reflection Radiometer) instrument flying onboard Aqua (EOS PM-1) mission (Aumann et al. 2003; Susskind et al. 2003). The Atmospheric Infrared Sounder (AIRS), together with the Advanced Microwave Sounding Unit (AMSU) and the Humidity Sounder for Brazil (HSB) retrieve atmospheric profiles and generate geophysical products on a global scale. Similar to Terra's orbit, the near polar inclination $\left(98^{\circ}\right)$ and sun-synchronous orbit of Aqua also samples at two different local time periods (1:30 PM and 1:30 AM), to measure geophysical data in daytime and nighttime except polar area.

\subsection{Atmospheric Variables}

\subsubsection{Temperature}

One of the key factors resulting from global climate change is the fluctuation or increase in temperature. In this study, we choose four different types of land surface temperature data products (from AGCMs and satellite observations) to study spatial distribution of temperature trends over the Tibetan Plateau. They are: (1) JRA-25 surface temperature values in the 2-dimensional physics monitor data (fcst_phy2m), (2) the monthly mean 2-meter air temperature in ERA-interim, (3) 8-day AIRS level 3 standard product (AIRX3ST8) processed by using daily weighted mean land surface temperature values from AIRS and AMSU radiances, and (4) 8-day MODIS land surface temperature product (MOD11C2). The observed AIRS and MODIS temperature values are averages of daytime and nighttime values.

\subsubsection{Snow}

The snowfall rate, snow depth, and time-varying snow extent are associated with the atmospheric circulations that are related to the interaction between temperature, humidity, and pressure system. Presumably, the snow depth and coverage have an anti-correlation with the temperature. Thus, the use of snow related products could indirectly validate land temperature data. Here, we used the monthly mean snow depth data from the ERA-interim model, the snow depth analysis (anl_snow106_mdl) data from the JRA-25 model, and the 8-day MODIS snow product (MOD10C2) (Che et al. 2008), to study the snow variations over the Tibetan Plateau.

\subsubsection{Precipitation}

The patterns of precipitation frequency, intensity, and concentration in the tropics and the subtropics (within $\pm 35^{\circ}$ latitudes) are measured since November 1997 by the international satellite radiometry mission, TRMM. The precipitation data sets used in this study are the frequency of rainfall element in 2-dimensional physics monitor data (fcst_phy2m) from the JRA-25 model, and the TRMM level 3 monthly rainfall estimate (3B43) data, over the Tibetan Plateau and its vicinity.

\subsubsection{Water Vapor Pressure}

The evaporation of surface rainfall or the equivalent water of snowfall has a connection with the intensity of the water vapor pressure. In other words, the water vapor pressure is a variable to verify the fidelity of precipitation and temperature products, although the complete quantification requires more complicated dynamics, such as air humidity variations, its transports, and their interactions. Three types of data are used in this study: (1) AIRS level 3 water vapor pressure in the 8-day standard product (AIRX3ST8), (2) Monthly mean of total column water vapor from the ERAinterim model, and (3) the precipitable water element in 2-dimensional physics monitor data (fcst_phy $2 \mathrm{~m}$ ) from the JRA-25 model.

\subsection{Processing Method}

An identical procedure is used to compute the time 
series and the trend of atmospheric variables over the Tibetan Plateau using the satellite observations and the model data products.

For JRA-25, a geographical window between $63 \sim$ $117^{\circ} \mathrm{E}$ and $18 \sim 45^{\circ} \mathrm{N}$ is used to extract values with a time span from 1979 to 2009 . The time series over each $1.125^{\circ} \times$ $1.125^{\circ}$ grids (T106) is generated and then a trend or a slope is estimated for each time series from 1979 to 2009, for each of the data grids. For ERA-interim, a geographical window between $66 \sim 108^{\circ} \mathrm{E}$ and $18 \sim 45^{\circ} \mathrm{N}$ is used to extract data in each $1.5^{\circ} \times 1.5^{\circ}$ grid with a time span from 1989 to 2009 . The time series of each grid is then generated and trends for each of the time series are estimated.

For the TRMM data, a geographical window between $65 \sim 110^{\circ} \mathrm{E}$ and $20 \sim 45^{\circ} \mathrm{N}$ is used to extract data with a horizontal resolution of $0.25^{\circ} \times 0.25^{\circ}$ and a time span from 1999 to 2009. The time series of each grid is then generated and trends for each of the time series are estimated.

It should be noted that the time span used to calculate trends in this study was equal to or shorter than the available time span since we attempted to obtain complete annual cycles instead of removing seasonal signals. For the MODIS data, a geographical window bounded in between $65 \sim 110^{\circ} \mathrm{E}$ and $20 \sim 45^{\circ} \mathrm{N}$ is used with a horizontal resolution of $0.5^{\circ} \times 0.5^{\circ}$. The time series of each grid and its linear trend for each of the atmospheric variables are generated over a time span from 2001 to 2009. Finally, for the AIRS data, the geographical window between $65 \sim 110^{\circ} \mathrm{E}$ and 20 $\sim 45^{\circ} \mathrm{N}$ with a horizontal resolution of $1^{\circ} \times 1^{\circ}$ is used to extract data and compute time series and trends for each of the atmospheric variables. A summary of data (satellite observations and model outputs) used and their resolutions is shown in Table 1. In this comparison study, it is noted that shortest time series is from AIRS (2003 2009), while the longest time series is from JRA-25 (1979 2009).

Figure 2 shows the comparison of land surface temperature time series from satellite observations (MODIS and AIRS) and from models (ERA-interim and JRA-25) averaged value over a region in the Tibetan Plateau (white rectangle, Fig. 1), over the time span $2003 \sim 2009$. Dashed horizontal lines are the estimated biases of each data set: $-0.29,-1.05,-3.12$, and $-2.01^{\circ} \mathrm{C}$, for AIRS, MODIS, JRA-25 and ERA-interim, respectively, which indicates significant relative offsets in surface temperature observed and predicted by the models. Figure 2 shows that the annual variations from observations and models approximately agree in amplitudes and in phases, but with observations usually warmer than model values during the winter and hotter than the model temperature values during the summer. The observed relative biases are large: almost $1^{\circ} \mathrm{C}$ between MODIS and AIRS, and up to $3^{\circ} \mathrm{C}$ between AIRS and JRA-25 model values.

\section{RESULT AND DISCUSSIONS}

A series of plots in Figs. $3 \sim 7$ illustrate the spatial distribution of trends for each of the atmospheric variables from satellite observations and models over the Tibetan Plateau. The corresponding elevation-dependent distribution trends for each of the variables are also shown. The trend el-

Table 1. Summary of data products used.

\begin{tabular}{|c|c|c|c|c|c|}
\hline Variable & Data source & Data element & Resolution & Data span & Sampling rate \\
\hline \multirow{4}{*}{ Temperature } & JRA-25 & \multirow{4}{*}{ temperature $\left({ }^{\circ} \mathrm{C}\right)$} & $1.125^{\circ} \times 1.125^{\circ}$ & $1979 \sim 2009$ & monthly \\
\hline & ERA-interim & & $1.5^{\circ} \times 1.5^{\circ}$ & $1989 \sim 2009$ & monthly \\
\hline & AIRS & & $1^{\circ} \times 1^{\circ}$ & $2003 \sim 2009$ & 8-day \\
\hline & MODIS & & $0.5^{\circ} \times 0.5^{\circ}$ & $2001 \sim 2009$ & 8-day \\
\hline \multirow{3}{*}{ Snow } & ERA-interim & depth (m) & $1.5^{\circ} \times 1.5^{\circ}$ & $1989 \sim 2009$ & monthly \\
\hline & MODIS & fractional cover $(\%)$ & $0.5^{\circ} \times 0.5^{\circ}$ & $2001 \sim 2009$ & 8-day \\
\hline & JRA-25 & $\begin{array}{l}\text { snowfall rate water } \\
\text { equivalent }\left(\mathrm{mm} \text { day }^{-1}\right)\end{array}$ & $1.125^{\circ} \times 1.125^{\circ}$ & $1979 \sim 2009$ & monthly \\
\hline \multirow{2}{*}{ Precipitation } & JRA-25 & frequency $(\%)$ & $1.125^{\circ} \times 1.125^{\circ}$ & $1979 \sim 2009$ & monthly \\
\hline & TRMM & rainfall rate $\left(\mathrm{mm} \mathrm{day}^{-1}\right)$ & $0.25^{\circ} \times 0.25^{\circ}$ & $1999 \sim 2009$ & monthly \\
\hline \multirow{3}{*}{ Water vapor pressure } & AIRS & \multirow{3}{*}{ pressure $\left(\mathrm{kg} \mathrm{m}^{-2}\right)$} & $1^{\circ} \times 1^{\circ}$ & $2003 \sim 2009$ & 8-day \\
\hline & ERA-interim & & $1.5^{\circ} \times 1.5^{\circ}$ & $1989 \sim 2009$ & monthly \\
\hline & JRA-25 & & $1.125^{\circ} \times 1.125^{\circ}$ & $1979 \sim 2009$ & monthly \\
\hline
\end{tabular}




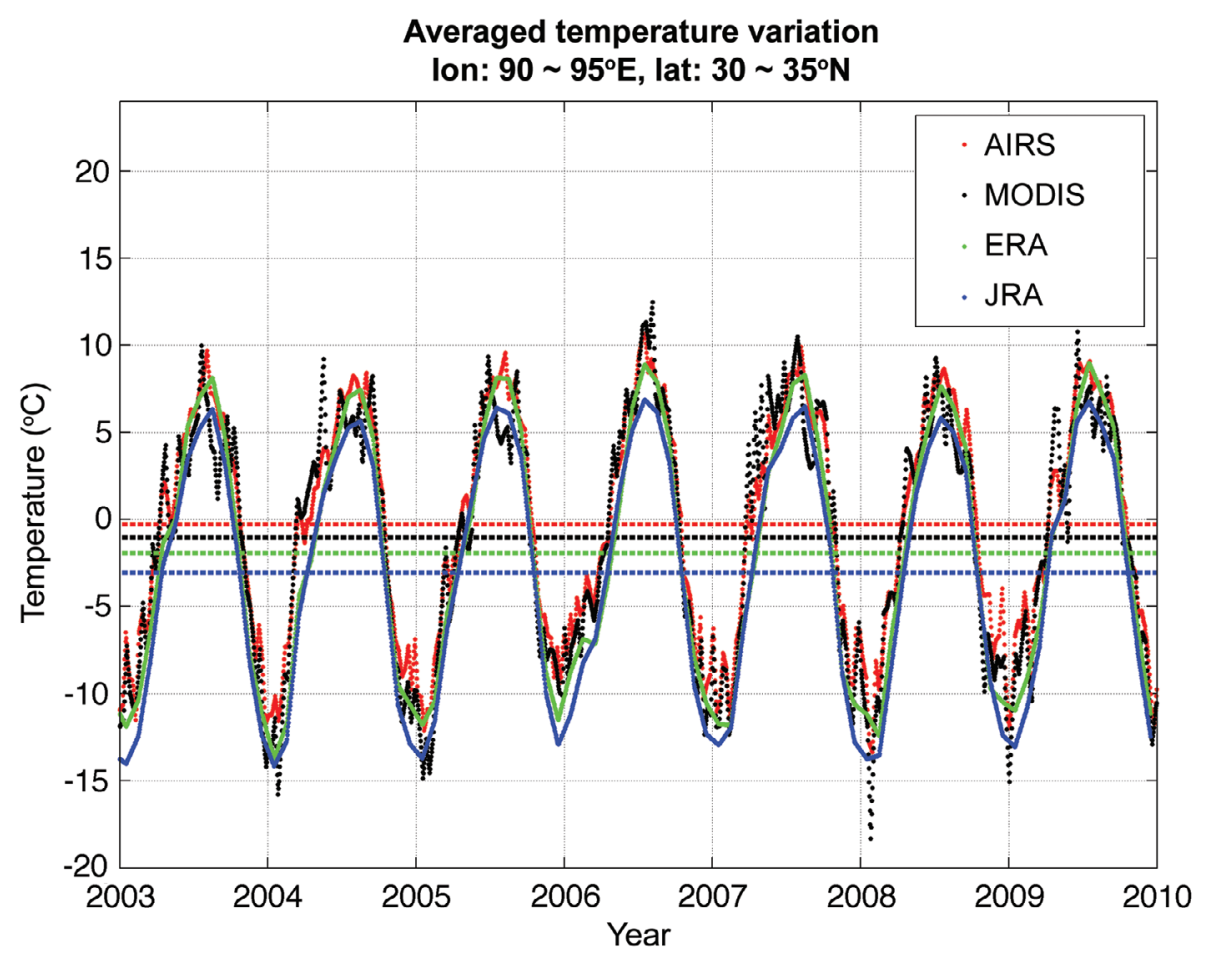

Fig. 2. Comparison of temperature time series from observations (MODIS and AIRS) and models (ERA-interim and JRA-25) averaged over a region in the Tibetan Plateau (white rectangle, Fig. 1), $2003 \sim 2009$. Dashed horizontal lines are the estimated biases of each data set.

evation-dependency are computed from the arithmetic mean of each $100 \mathrm{~m}$ in elevation change covering the Tibetan Plateau and its vicinity $\left(70 \sim 108^{\circ} \mathrm{E}\right.$ and $27 \sim 41^{\circ} \mathrm{N}$, Fig. 1). Grey dots in the "trend versus elevation" panels are trends for each of the grids. Dashed lines are averaged trends over different elevations (refer to right y-axis). Dashed vertical lines in each of the trend versus elevation plots between $4000 \sim 5000$ m elevations, are used to study the characteristics of the trends for each atmospheric variable at the top of the Tibetan Plateau.

Despite the apparent coherence at seasonal signals for the observed and model temperature data (Fig. 2), except for relative biases as large as $3^{\circ} \mathrm{C}$, Fig. 3 shows that the temperature trends (2003 2009) over the Tibetan Plateau and its vicinity are completely different for JRA-25, ERA-interim, AIRS, and MODIS. In particular, model temperature trends are largely near zero, while the satellite temperature trends are approximately between $0.05 \sim 0.25^{\circ} \mathrm{C} \mathrm{yr}^{-1}$. The MODIS trend seems to be increasing in between the $4000 \sim 5000 \mathrm{~m}$ altitude, while AIRS and the model temperature trends (JRA-25 and ERA-interim) are decreasing in between the $4000 \sim 5000 \mathrm{~m}$ altitude. Figure 3 shows that the temperature trend analysis probably requires a much longer time span than 7 years $(2003 \sim 2009)$ for AIRS, or for MODIS (2001 $\sim 2009$ ), and thus the trends are probably unreliable. The model time series is over 20 years (ERA-interim, 1989 2009) and 30 years (JRA-25, $1979 \sim 2009)$. The estimated average land surface temperature trends between the $4000 \sim$
$5000 \mathrm{~m}$ elevation over the Tibetan Plateau are approximately: $0.01,0.04,0.03^{\circ} \mathrm{C} \mathrm{yr}^{-1}$, for JRA-25, ERA-interim, and MODIS, respectively. It is perhaps in qualitative agreement with the in situ temperature trend estimate of $0.3^{\circ} \mathrm{C}_{\text {decade }}{ }^{-1}$ over the last three decades, or, $0.01^{\circ} \mathrm{C} \mathrm{yr}^{-1}$, above $4000 \mathrm{~m}$ altitude over the Tibetan Plateau (Liu and Chen 2000; Xu et al. 2009).

Figures $4 \mathrm{a}$ and $4 \mathrm{~b}$ display the trends for both the depth and the fractional cover of snow from models (ERA-interim and JRA-25) and MODIS, respectively. Here the model and the satellite observation (MODIS) show qualitative agreement: decreased rate of snow depth and fractional cover of snow in the western and southern Tibetan Plateau. The southern to the southwestern edge of Tibetan Plateau has a snow reduction of $-0.8 \%$ per year as shown by the MODIS trend. In elevation-dependent versus trend plots, it is noted that the snow depth and the fractional snow cover trends increase in between $4000 \sim 5000 \mathrm{~m}$.

Figures $5 \mathrm{a}$ and $5 \mathrm{~b}$ show the trends of frequency of rainfall distribution $\left(\% \mathrm{yr}^{-1}\right)$ and trends of snowfall rate $(\mathrm{mm}$ day $^{-1} \mathrm{yr}^{-1}$ ) from JRA-25 model, $1979 \sim 2009$, respectively, and their trend elevation-dependency plots. Figure 5 shows that the rate of frequency of rainfall and snowfall rate over the central or the entire Tibetan Plateau has been increasing during the last three decades. The frequency of rainfall and snowfall rate tends to be more intensive as the elevation increases. However, Fig. 6 shows the amount of rainfall has no significant change over the entire Plateau as observed by 
(a)

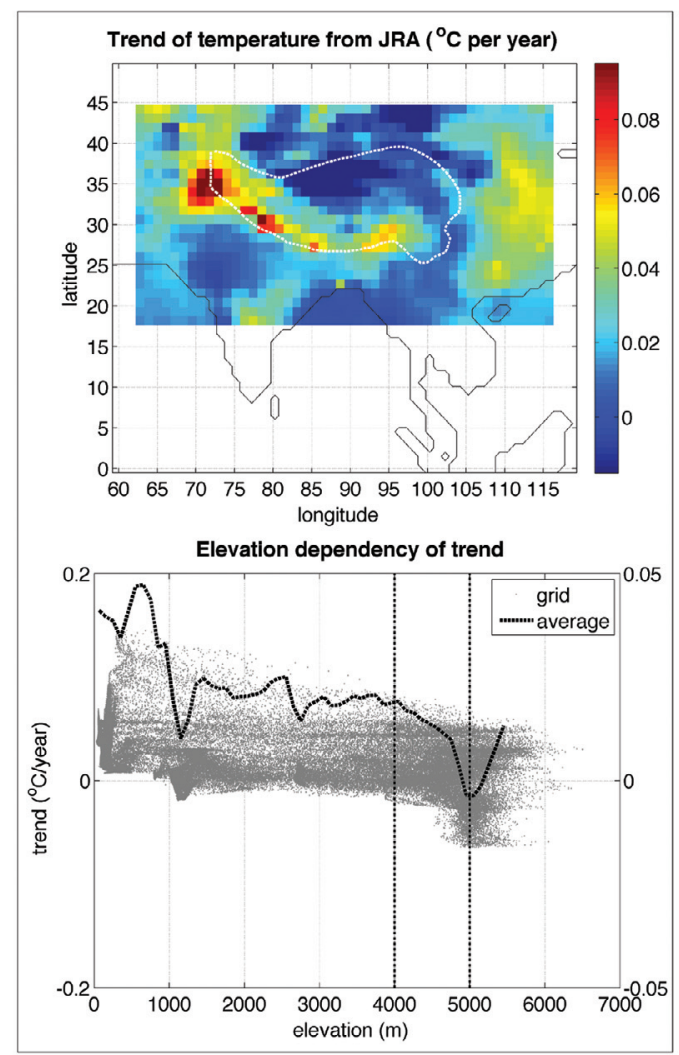

JRA-25

(b)

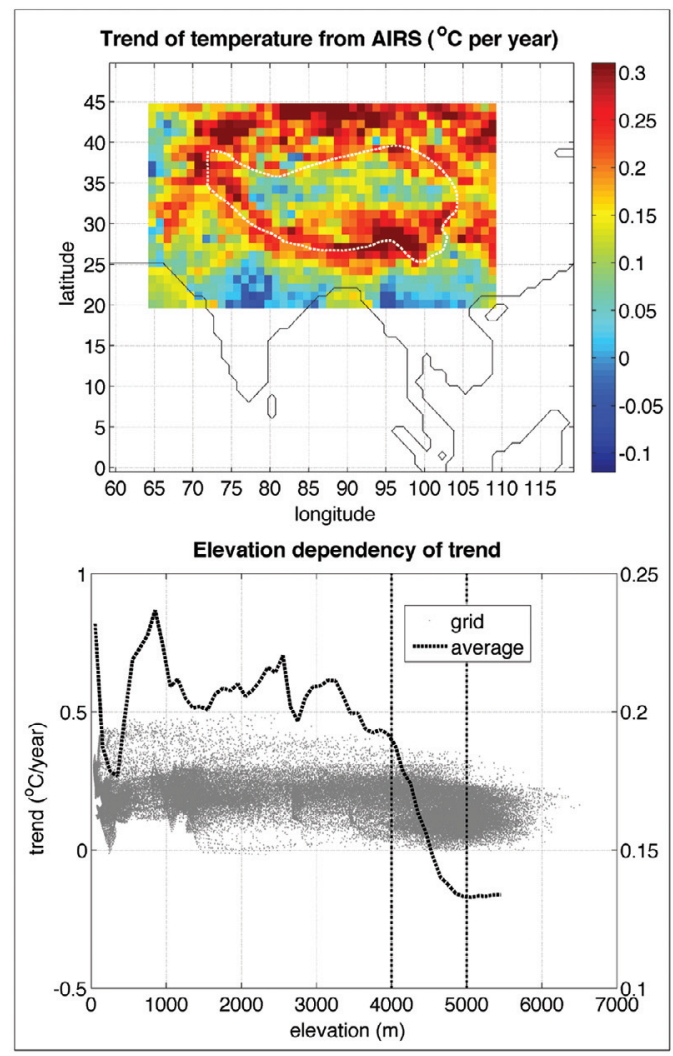

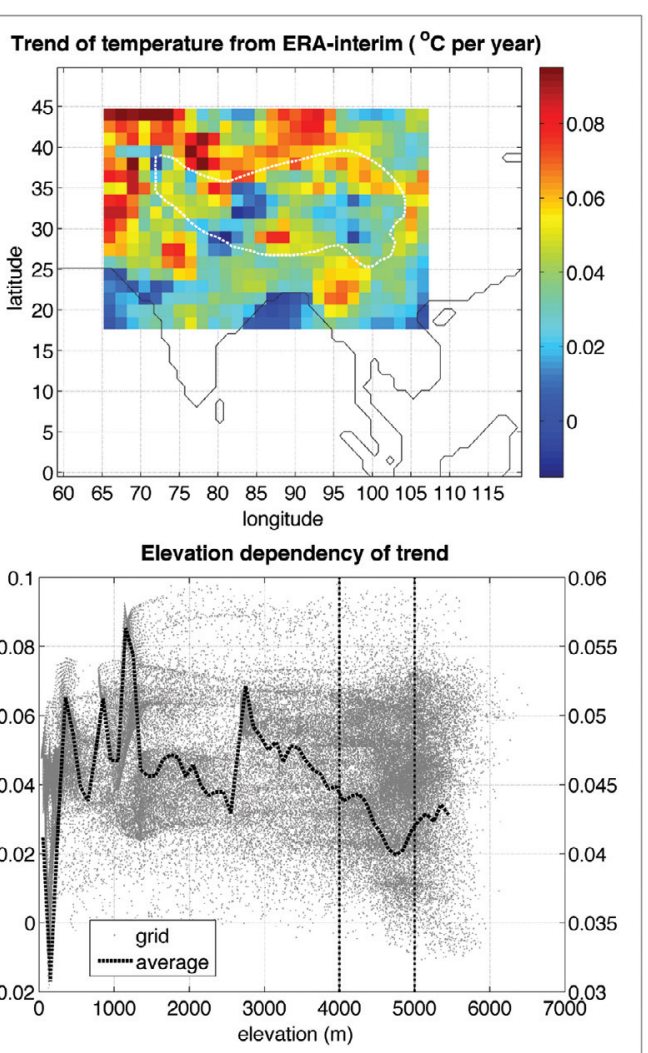

ERA-interim
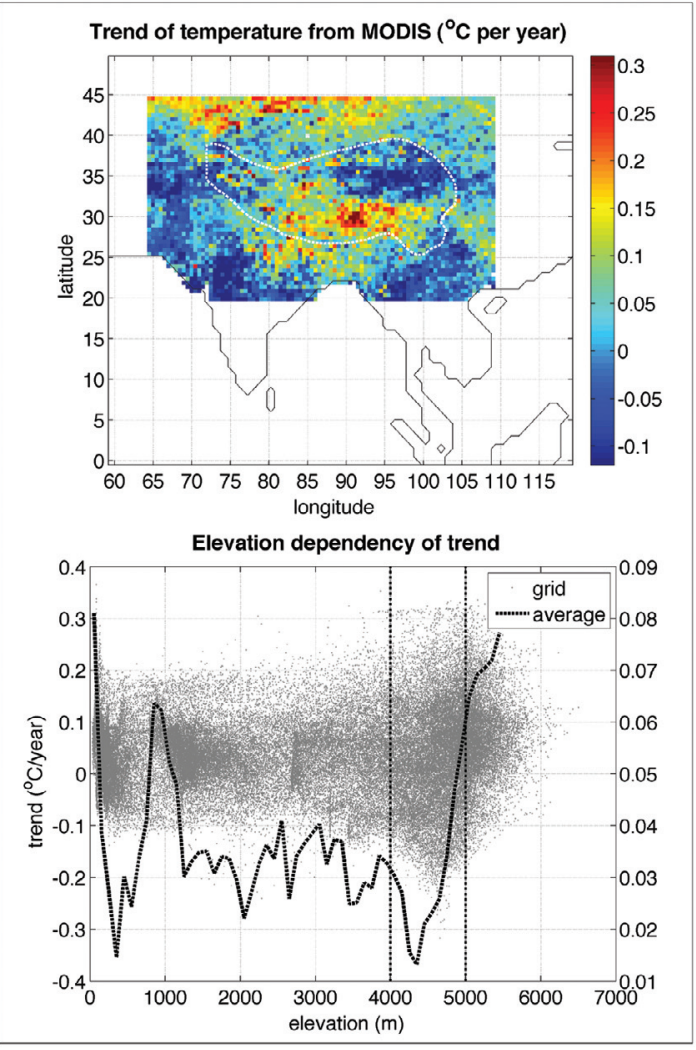

Fig. 3. Temperature trend $\left({ }^{\circ} \mathrm{C} \mathrm{yr}^{-1}\right)$ over the Tibetan Plateau and the vicinity from atmospheric general circulation models [JRA-25 and ERA-interim, top panel of (a)], and from observations [AIRS and MODIS, top panel of (b)], and their corresponding trends as a function of elevation [bottom panel of (a) and (b), respectively]. Grey dots in the "trend versus elevation" panels are trends for each of the grids. Dashed lines are averaged trends over different elevations (refer to right y-axis). Dashed vertical lines bound the $4000 \sim 5000 \mathrm{~m}$ elevations. 
(a) Trend of snow depth from ERA-interim ( $m$ per year)
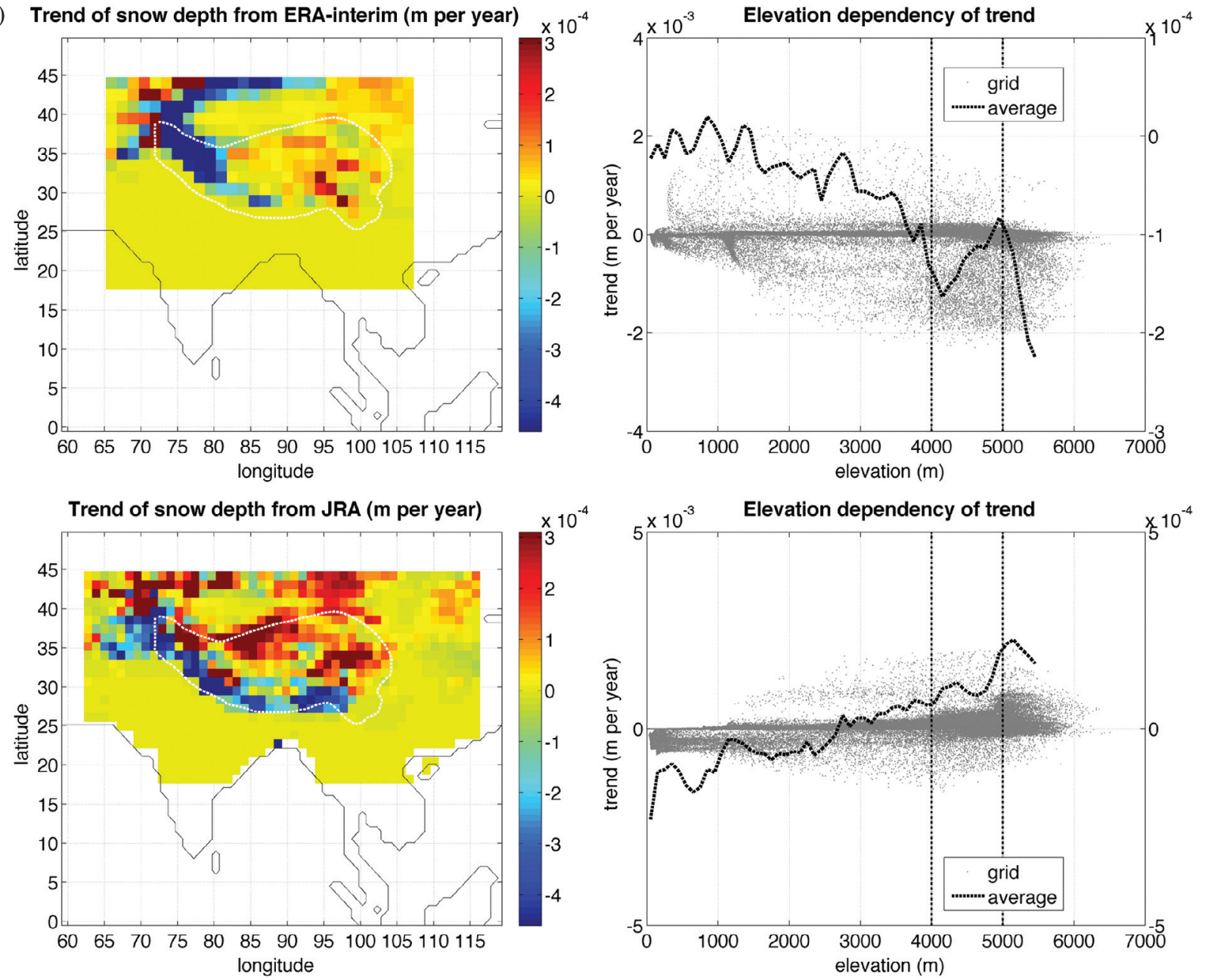

(b)
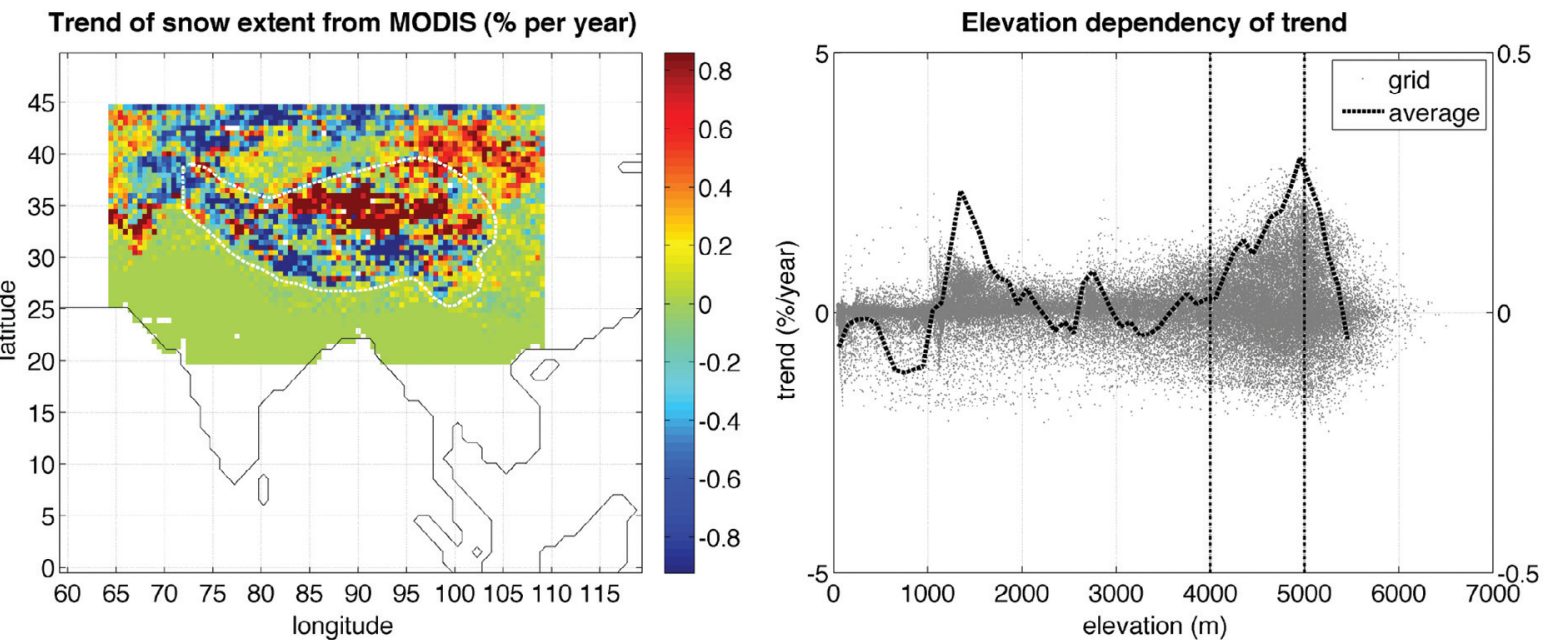

Fig. 4. (a) Snow depth trend ( $\mathrm{m} \mathrm{yr}^{-1}$, scaled by $10^{-4}$ ) over the Tibetan Plateau and the vicinity from the JRA-25 and ERA-interim models (left) and the corresponding trends as a function of elevation (right). Grey dots in the right panels are trends in each of the grids. Dashed lines are averaged trends

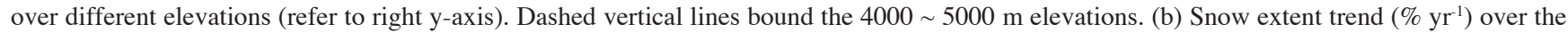
Tibetan Plateau and the vicinity from MODIS satellite observations (left) and the corresponding trend as a function of elevation (right). Grey dots in the right panel are trends in each of the grids. Dashed lines are averaged trends over different elevations (refer to right $y$-axis). Dashed vertical lines bound the $4000 \sim 5000$ m elevations. 
(a) Trend of rainfall frequency from JRA (\% per year)

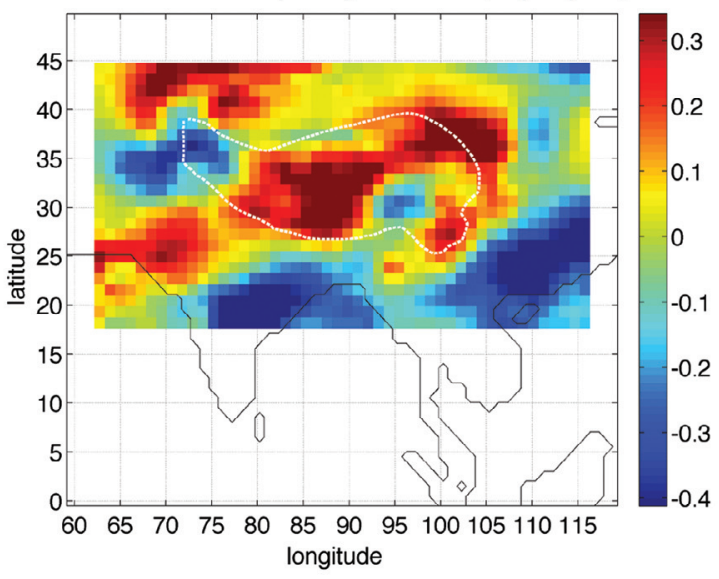

Elevation dependency of trend

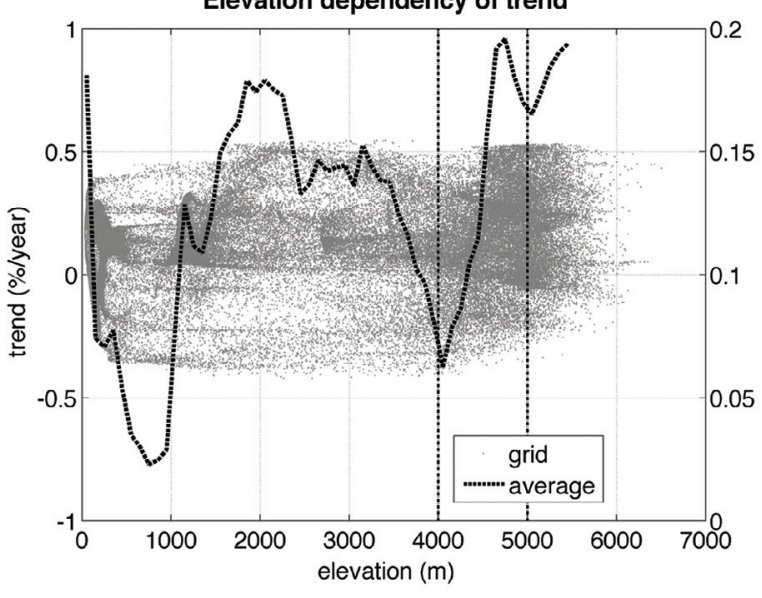

(b) Trend of snowfall rate from JRA ( $\mathrm{mm} /$ day per year)

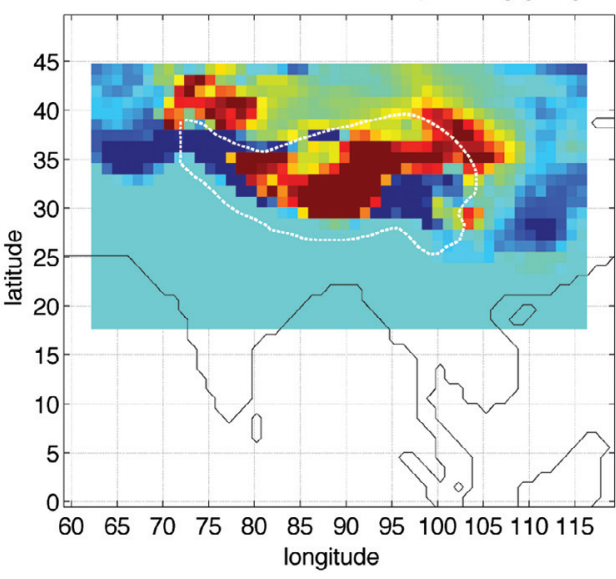

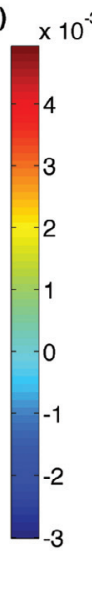

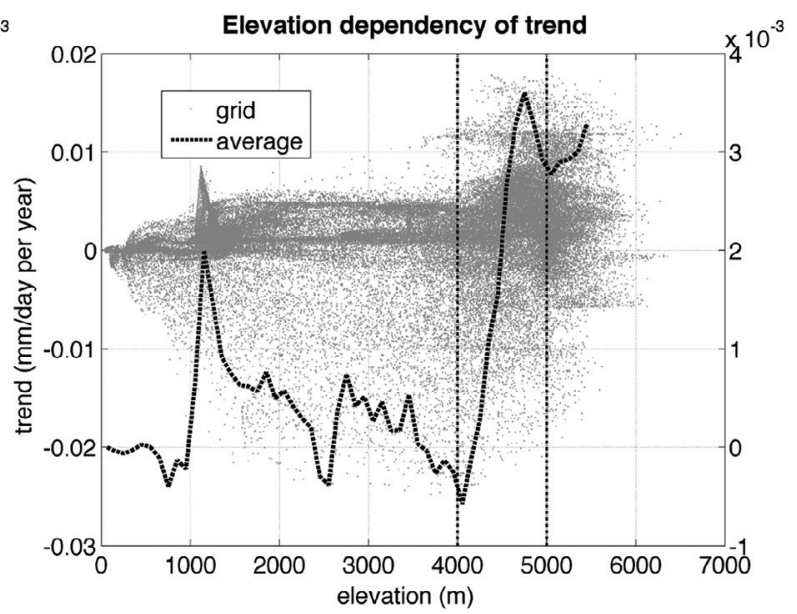

Fig. 5. (a) Trend of rainfall frequency distribution $\left(\% \mathrm{yr}^{-1}\right)$ over the Tibetan Plateau and the vicinity from the JRA-25 model (left) and the corresponding trend as a function of elevation (right). Grey dots in the right panels are trends in each of the grids. Dashed lines are averaged trends over different elevations (refer to right y-axis). Dashed vertical lines bound the $4000 \sim 5000 \mathrm{~m}^{2}$ elevations. (b) Trend of snowfall rate (mm date $\mathrm{yr}^{-1}$ ) over the Tibetan Plateau and the vicinity from the JRA-25 model (left) and the corresponding trend as a function of elevation (right). Grey dots in the right panels are trends in each of the grids. Dashed lines are averaged trends over different elevations (refer to right y-axis). Dashed vertical lines bound the $4000 \sim 5000$ m elevations.

Trend of rainfall rate from TRMM ( $\mathrm{mm} /$ day per year)

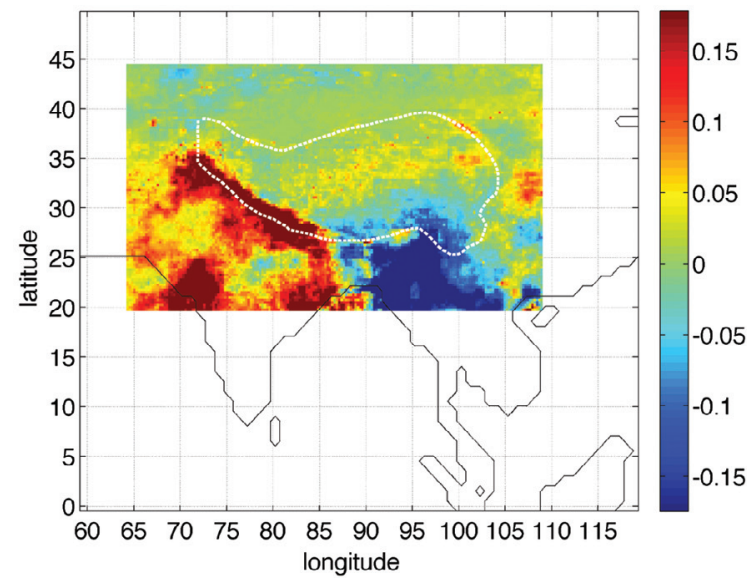

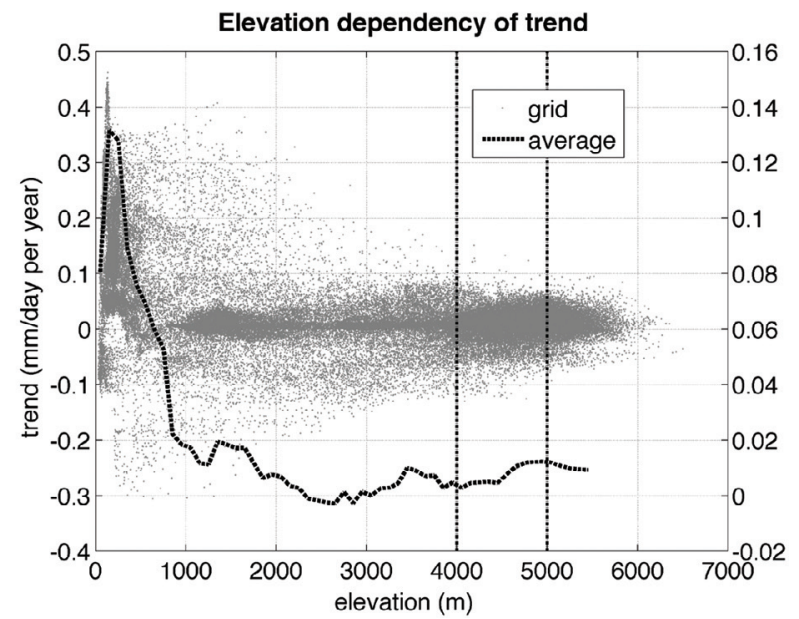

Fig. 6. Trend of rainfall rate ( $\mathrm{mm}$ date $\left.\mathrm{e}^{-1} \mathrm{yr}^{-1}\right)$ over the Tibetan Plateau and the vicinity from TRMM satellite observations (left) and the corresponding trend as a function of elevation (right). Grey dots in the right panels are trends in each of the grids. Dashed lines are averaged trends over different elevations (refer to right $y$-axis). Dashed vertical lines bound the $4000 \sim 5000$ m elevations. 
TRMM during the last decade, $1999 \sim 2009$, except at the southwestern Plateau, or the western Himalaya, presumably due to the intensifying summer monsoon. The southeastern Plateau and its vicinity have a decrease in rainfall rate.

Figure 7 shows the water vapor pressure observed by AIRS (2003 2009), and by the models (ERA-interim,

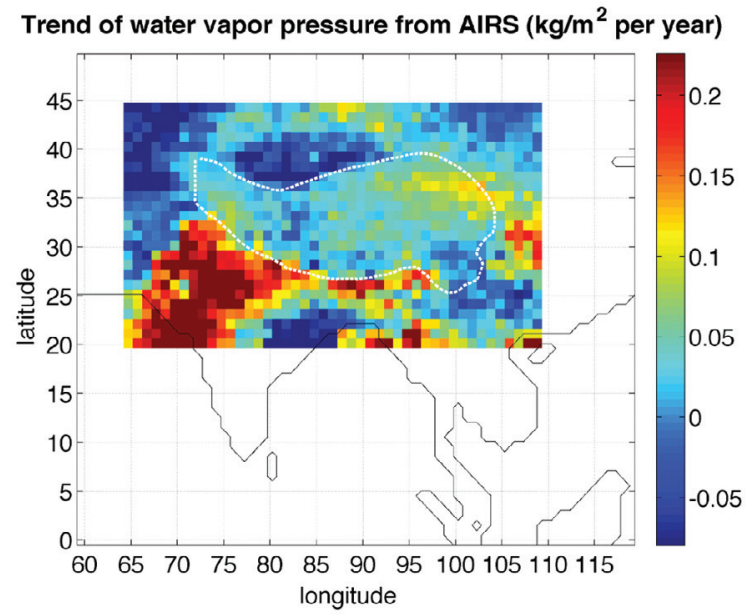

Trend of WVP from ERA-interim $\left(\mathrm{kg} / \mathrm{m}^{2}\right.$ per year)
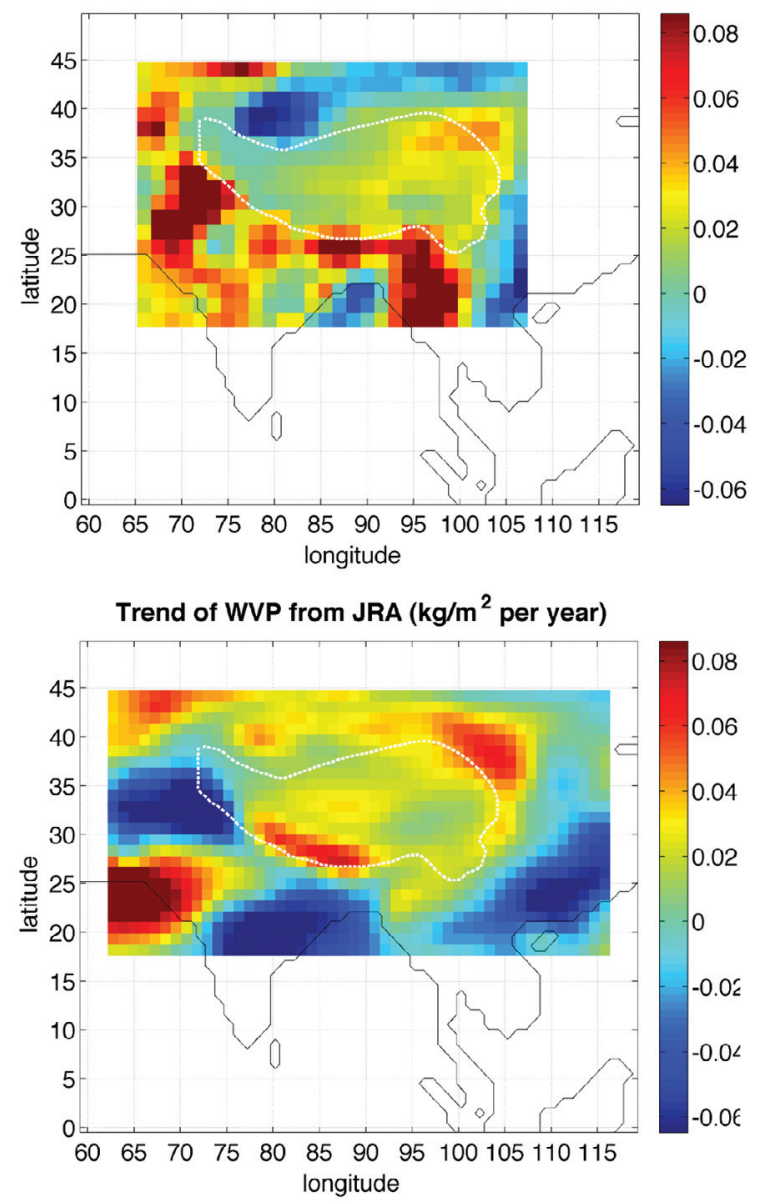

$1989 \sim 2009$, and JRA-25, $1979 \sim 2009$ ), respectively, with the associated trend elevation-dependent plots. An intensive increase of water vapor (from AIRS, ERA-interim, and to a lesser extent, JRA-25) around southern and southwestern edge of the Tibetan Plateau (Fig. 7) agrees with the increasing rate of rainfall in the same region (Figs. 5 and 6).
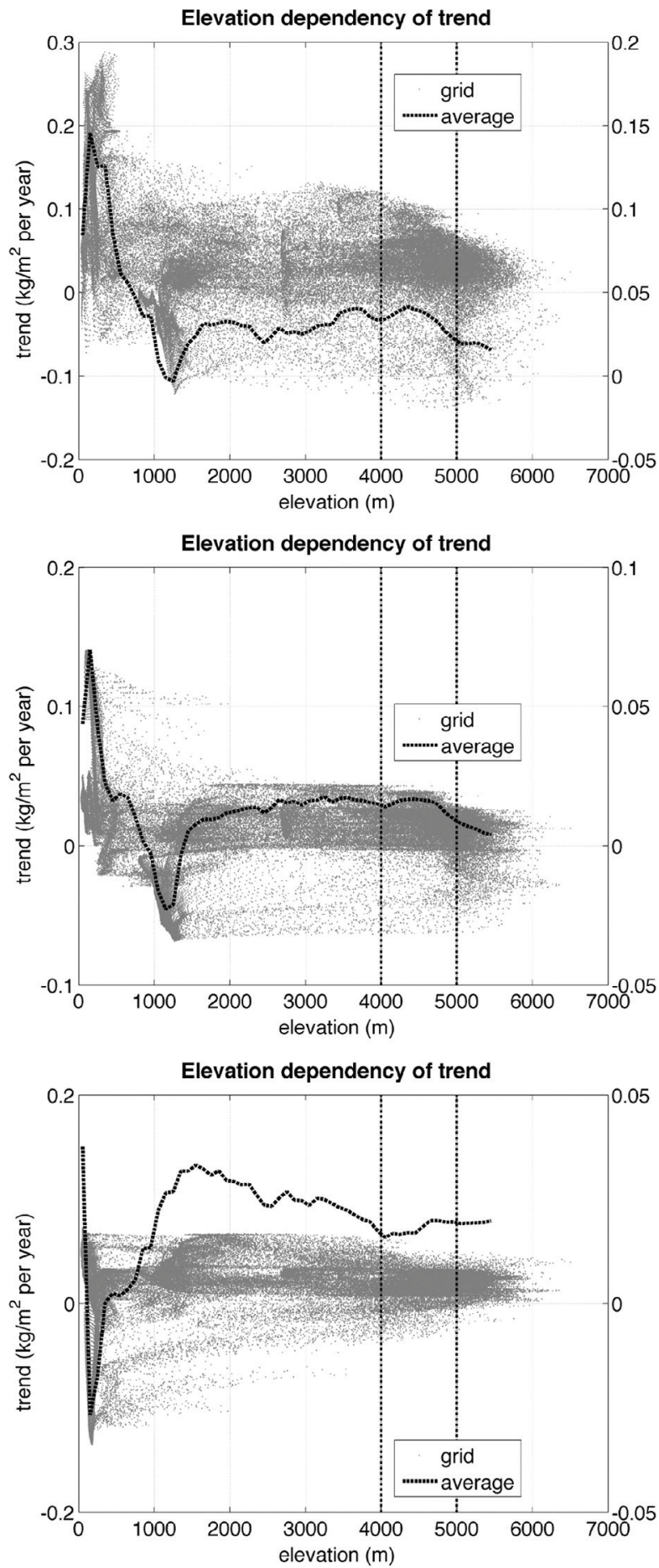

Fig. 7. Trend of water vapor pressure $\left(\mathrm{kg} \mathrm{m}^{-2} \mathrm{yr}^{-1}\right)$ over the Tibetan Plateau and the vicinity from AIRS satellite observation, and the ERA-interim and JRA-25 models (left) and the corresponding trends as a function of elevation (right). Grey dots in the right panels are trends in each of the grids. Dashed lines are averaged trends over different elevations (refer to right y-axis). Dashed vertical lines bound the $4000 \sim 5000 \mathrm{~m}$ elevations. 


\section{CONCLUSION}

The data provided by satellite missions in this study may be too short in time span to reflect longer-term secular trend. The trend computations for atmospheric parameters observed by MODIS, TRMM, and AIRS only available for 7 to 10 years long. Overall, the satellite observations and model outputs compared in the form of secular trends over varying data spans (from 7 to 30 years), at best, show general qualitative agreements. However, these data sets (model and satellite observations), which have spatial sampling over the entire Tibetan Plateau and temporally from 8 days to monthly, have the potential towards quantifying the atmospheric and environmental variables to study climate change over the Tibetan Plateau and its vicinity.

Acknowledgements This research is partially supported by a grant from Ohio State University's Climate, Water and Carbon Program (http://cwc.osu.edu). The Shanghai Astronomical Observatory research is funded by grants from the National Nature Science Foundation of China (10603011), and the National High Technology Research and Development Program 863 (863 Program No. 2009AA12Z307). We thank the editors, C. Hwang, B. Chao and two anonymous reviewers for their constructive comments. The MODIS, AIRS data products are from NASA, via NASA/GSFC. The JRA25 model product is obtained from the Japan Meteorological Agency, and the ERA-interim model product is from The European Centre for Medium-Range Weather Forecasts.

\section{REFERENCES}

Aumann, H. H., M. T. Chahine, C. Gautier, M. D. Goldberg, E. Kalnay, L. M. McMillin, H. Revercomb, P. W. Rosenkranz, W. L. Smith, D. H. Staelin, L. L. Strow, and J. Susskind, 2003: AIRS/AMSU/HSB on the Aqua Mission: Design, science objectives, data products, and processing systems. IEEE Trans. Geosci. Remote Sensing, 41, 253-264, doi: 10.1109/TGRS. 2002.808356. [Link]

Barry, R. G., 1990: Changes in mountain climate and glaciohydrological responses. Mt. Res. Dev., 10, 161-170.

Beniston, M., 1994: Introduction. In: Mountain Environments in Changing Climates, Routledge, xxiv-xxxi.

Che, T., L. Xin, R. Jin, R. Armstrong, and T. Zhang, 2008: Snow depth derived from passive microwave remotesensing data in China. Ann. Glaciol., 49, 145-154, doi: 10.3189/172756408787814690. [Link]

Dee, D. P. and S. Uppala, 2009: Variational bias correction of satellite radiance data in the ERA-interim reanalysis. Q. J. R. Meteorol. Soc., 135, 1830-1841, doi: 10.1002/ qj.493. [Link]

Hansen, J. and S. Lebedeff, 1987: Global trends of measured surface air temperature. J. Geophys. Res., 92, 13345-13372, doi: 10.1029/JD092iD11p13345. [Link]
Hingane, L. S., K. R. Kumar, and B. V. R. Murty, 1985: Long-term trends of surface air temperature in India. Int. J. Climatol., 5, 521-528, doi: 10.1002/joc.3370050 505. [Link]

Le Treut, H., R. Somerville, U. Cubasch, Y. Ding, C. Mauritzen, A. Mokssit, T. Peterson, and M. Prather, 2007: Historical overview of climate change. In: Solomon, S., D. Qin, M. Manning, Z. Chen, M. Marquis, K. B. Averyt, M. Tignor, and H. L. Miller (Eds.), Climate Change 2007: The Physical Science Basis, Contribution of Working Group I to the Fourth Assessment Report of the Intergovernmental Panel on Climate Change, Cambridge University Press, Cambridge, United Kingdom and New York, NY, USA.

Lemke, P., J. Ren, R. B. Alley, I. Allison, J. Carrasco, G. Flato, Y. Fujii, G. Kaser, P. Mote, R. H. Thomas, and T. Zhang, 2007: Observations: Changes in snow, ice and frozen ground. In: Solomon, S., D. Qin, M. Manning, Z. Chen, M. Marquis, K. B. Averyt, M. Tignor, and H. L. Miller (Eds.), Climate Change 2007: The Physical Science Basis, Contribution of Working Group I to the Fourth Assessment Report of the Intergovernmental Panel on Climate Change, Cambridge University Press, Cambridge, United Kingdom and New York, NY, USA.

Liu, X. and B. Chen, 2000: Climatic warming in the Tibetan Plateau during recent decades. Int. J. Climatol., 20, 1729-1742, doi: 10.1002/1097-0088(20001130)20:14 $<1729:$ :AID-JOC556>3.0.CO;2-Y. [Link]

Onogi, K., J. Tsutsui, H. Koide, M. Sakamoto, S. Kobayashi, H. Hatsushika, T. Matsumoto, N. Yamazaki, H. Kamahori, K. Takahashi, S. Kadokura, K. Wada, K. Kato, R. Oyama, T. Ose, N. Mannoji, and R. Taira, 2007: The JRA-25 Reanalysis. J. Meteorol. Soc. Jpn., 85, 369-432, doi: 10.2151/jmsj.85.369. [Link]

Qiu, J., 2008: China: The third pole. Nature, 454, 393-395, doi: 10.1038/454393a. [Link]

Shrestha, A. B., C. P. Wake, P. A. Mayewski, and J. E. Dibb, 1999: Maximum temperature trends in the Himalaya and its vicinity: An analysis based on temperature records from Nepal for the period 1971-94. J. Climate, 12, 2775-2789, doi: 10.1175/1520-0442(1999)012<27 75:MTTITH>2.0.CO;2. [Link]

Solomon, S., D. Qin, M. Manning, Z. Chen, M. Marquis, K. B. Averyt, M. Tigora, and H. L. Miller (Eds.), 2007: Climate Change 2007: The Physical Science Basis, Contribution of Working Group I to the Fourth Assessment Report of the Intergovernmental Panel on Climate Change, Cambridge University Press, Cambridge, United Kingdom and New York, NY, USA, 996 pp.

Susskind, J., R. Atlas, C. Barnet, J. Blaisdell, L. Iredell, G. Brin, J. C. Jusem, F. Keita, L. Kouvaris, and G. Molnar, 2003: Current results from AIRS/AMSU/HSB. Proceedings of Thirteenth International TOVS Study 


\section{Conference.}

Wu, T. W. and Z. A. Qian, 2003: The relation between the Tibetan winter snow and the Asian summer monsoon and rainfall: An observational investigation. J. Climate, 16, 2038-2051.

Xu, B., J. Cao, J. Hansen, T. Yao, D. R. Joswia, N. Wang, G. Wu, M. Wang, H. Zhao, W. Yang, X. Liu, and J. He, 2009: Black soot and the survival of Tibetan glaciers. Proc. Natl. Acad. Sci. USA, 106, 22114-22118, doi: 10.1073/pnas.0910444106. [Link]

Xu, X., C. Lu, X. Shi, and S. Gao, 2008: World water tower: An atmospheric perspective. Geophys. Res. Letts., 35, L20815, doi: 10.1029/2008GL035867. [Link]

Yao, T., J. Pu, A. Lu, Y. Wang, and W. Yu, 2007: Recent glacial retreat and its impact on hydrological processes on the Tibetan Plateau, China, and surrounding regions. Arct. Antarct. Alp. Res., 39, 642-650, doi: 10.1657/15230430(07-510)[YAO]2.0.CO;2. [Link] 